Germany, Great Britain, Holland, Italy and Switzerland. This is the outcome of an experiment carried out in 1952, when television programmes were exchanged between Paris and London, and followed by the tremendous success of the relaying to certain countries of Western Europe of the 1953 Coronation broadcast of the B.B.C. It should perhaps be explained that the problems involved in disseminating a television programme among European countries are more complicated than those confronting tho nation-wide networks of the United States of America. In America, the television system complies with a uniform standard throughout, the language is the same everywhere, and the relay links, whether line or radio, are under the control of one organization - the Bell System.

In Europe, there are four standards of television in operation, there are at least six languages in use, and the eommunications networks are owned and operated by the individual national administrations. The achievement of programme interchange now undergoing a practical trial is the result of friendly and happy relationships between both the administrations and the technical experts of all the countries concerned. In the course of this interchange, the television signals may have to be converted from the British standard of 405-line definition to either of the French standards 819- and 441-lines, or to that of the 625-line standard adopted in most other European countries. But the problems of conversion from one standard to another and in either direction have now been largely solved following the pioneer work carried out in England and France. The language difficulty is usually resolved by the provision of independent commentators at the scene of the originating programme, thus providing the speech accompaniment appropriate to the various countries in which reception is taking place. On the opening day, June 6, of the present experiments, the afternoon programme originated in Montreux, where a. Swiss national fête was in progress ; in the evening, viewers enjoyed a visit to Rome and the Vatican City, in the course of which the Pope spoke in five languages commenting on this important event in the history of television.

\section{Antiquity of the Australian Aborigines}

AN important article in No. 18 of the "Memoirs of the National Museum of Victoria, Melbourne" (1953) is one entitled "Geological Evidence in W Vestern Victoria relative to the Antiquity of the Australian Aborigines" by E. D. Gill, palæontologist at the Museum. The paper occupies sixty-seven pages and is illustrated with sections and photographs and a map. For the past fifty years prehistorians have advanced theories as to the cultural origins of the Australian aborigines and of the Tasmanians. Admittedly their stone industries are primitive in type, especially those of the latter. Suggestions have even been made that we have here to deal with Mousterians who, having arrived somehow in those parts, did not evolve any further. Some workers have long urged that the problem should be taken up energetically locally and sites found where a stratigraphical sequence of the cultures, as shown by the industries they have left behind, could be determined, and where a correlation between the archæological sequence so obtained and the geological record could be made. Much more investigation is still required on both these counts; but in both cases a start has been made. Gill's article deals, of course, with the latter. A short summary indicates the scope of recent advances in knowledge. Three periods of aboriginal occupation of the Lake Colongulac area are known: first, the time of the extinct giant marsupials before the local ash vulcanism, as shown by fossil dingo and a carved bone-the age is thought to be late Pleistocene; second, the Mid-Holocene arid period, as shown by a fossil aborigine in a loess dune ; and third, the very recent period. At Pejark Marsh a millstone proves the presence of aborigines as contemporary with the extinct marsupials before the local ash vulcanism. The age here is thought to be late Pleistocene or early Holocene. At Bushfield an axe and bones, etc., show that aborigines were present when the Tower Hill volcano first became active, about a thousand years ago. The work in Australia is not easy, whether for the archæologist or the Quaternary and Holocene geologist. But here is a beginning, and some day we shall have before us the sequence of Stone Age cultures in various parts of Australia and their correlation with the various phases of the late Quaternary and Holocene periods.

\section{Impact}

SINCE criminology is a elinical science, scientific methods of preventing crime must be directed in the first place to the personality of actual-or potential -criminals. Any medical and scientific measures capable of preventing the birth of children with brains malformed, underdeveloped or injured by lesions due to traumatisms or to toxic or infectious agents, and of preventing subjects born normal and healthy from suffering from any type of cerebral lesion can greatly contribute to the prevention of crime. This is the substance of an article by Olaf Kinberg in the spring number of Impact $(5$, No. 1. Unesco). Another article, by E. W. Golding, shows that newly established communities in underdeveloped areas may have to be self-supporting, at least in the early stages of development. Local resources of energy may thus assume considerable importance. This fact lends particular interest to the possibilities of such energy sources as wind, solar radiation, peat and waste vegetable matter. Frequently, the energy which could be made available from such sources could meet the needs of a population large enough to undertake the initial stages of development.

\section{Collected Papers of the Rowett Research Institute}

THE growing importance of agricultural research in Groat Britain is reflected in the number and scope of scientific publications emanating from the thirtyodd institutes and units connected with the Agricultural Research Council. One of the largest of these, the Rowett Research Institute, has for some time past made available for limited circulation to sister institutions lists and summaries of each year's collected papers. The papers for 1953 have now been made generally available under the title "Rowett Research Institute: Collected Papers with Summarized Account of Contents" (Vol. 10, pp. 24; obtainable from the Librarian, Rowett Research Institute, Bucksburn, Aberdeen; 2s. 6d., post paid). In this publication sixty-seven papers scattered over many scientific journals are listed title by title, and the accompanying summary by the director, Dr. D. P. Cuthbertson, is arranged to present the findings in a sequence of topics and development. The publication will be welcomed by many interested in 